\title{
Elevated Blood Urea Nitrogen Is a Predictive Factor for Intensive Care Unit Admission in Legionella Pneumonia
}

\author{
Yutaka Hashizume, ${ }^{1}$ Atsushi Takise, ${ }^{1}$ Yasuo Shimizu ${ }^{1}$ \\ Takeo Horie, ${ }^{1}$ Katsuaki Endou ${ }^{1}$ and Tadayoshi Kawata ${ }^{1}$
}

\section{Background}

Legionella pneumonia ( $L$. pneumonia) is a serious disease among patients with community-acquired pneumonia (CAP). Appropriate initial assessment of severity and admission to intensive care unit (ICU) can reduce mortality due to $L$. pneumonia. Here, the efficacy of using the current CAP scoring for recommending admission to ICU and other variables for initial management were evaluated.

\section{Methods}

The clinical characteristics of 11 patients diagnosed with $L$. pneumonia at Maebashi Red Cross Hospital from November 1999 to July 2010 were examined. The scoring systems of A-DROP (A : Age, D : Dehydration, R: Respiration, O : Orientation, and P: Blood Pressure) and CURB-65 (C: Confusion, U : Urea, R : Respiratory rate, B : Blood pressure, and A: Age) were used.

\section{Results}

Of the $11 L$. pneumonia patients, 6 were admitted to the ICU. By A-DROP and CURB-65 scoring systems, 4 cases were assessed as not severe. Among the parameters used in the scores, only elevated blood urea nitrogen (BUN) had significantly predictive potential for ICU admission (sensitivity $=100 \%$, specificity $=80 \%, \quad P<0.02$ ). Both A-DROP and CURB-65 scoring systems underestimated the severity of CAP caused by $L$. species.

\section{Conclusion}

In the case of $L$. pneumonia, elevated BUN level is important for assessing CAP severity and making ICU admission recommendations.

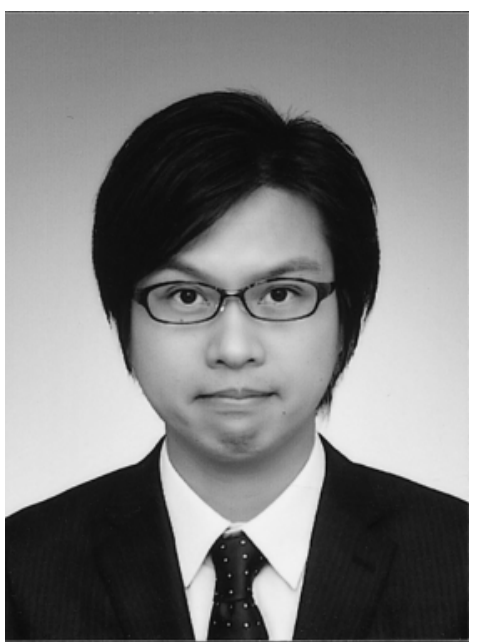

\section{Acknowledgement}

We thank medical staffs of Meabashi Red Cross Hospital.

\section{References}

1. Fraser DW, Tsai TR, Orenstein W, et al. Legionnaires' disease: Description of an epidemic of pneumonia. N Engl J Med 1977; 297(22) : 1189-1197.

2. Edelstein, PH, Cianciotto, NP. Legionella. In Mandell GL, Bennett JE, Dolin, R, editors. Principles and practice of infectious diseases, 6th ed. Churchill Livingstone, Philadelphia, PA, 2005, pp.2711-2724.

3. Haeuptle J, Zaborsky R, Fiumefreddo R, et al. Prognostic value of procalcitonin in Legionella pneumonia. Eur $\mathrm{J}$ Clin Microbiol Infect Dis 2009; 28(1) : 55-60.

4. Chalmers JD: ICU admission and severity assessment in community-acquired pneumonia. Crit Care 2009; 13(3): 156.

5. Cillóniz C, Ewig S, Polverino E, et al. Microbial aetiology of community-acquired pneumonia and its relation to severity. Thorax $2011 ; 66(4): 340-346$.

6. Miyashita N, Matsushima T, Oka M, et al. The JRS guidlines for the management of community-acquired pneumonia in adults: An update and new recommendations. Intern Med 2006 ; 45(7) : 419-428.

1 Department of Respiratory Medicine, Maebashi Red Cross Hospital, 3-21-36 Asahi-cho, Maebashi, Gunma 371-0014, Japan Received : October 28, 2013

Address: YUTAKA HASHIZUME Department of Respiratory Medicine, Maebashi Red Cross Hospital, 3-21-36 Asahi-cho, Maebashi, Gunma 371-0014, Japan 
7. Lim WS, van der Eerden MM, Laing R, et al. Defining community acquired pneumonia severity on presentation to hospital: An international derivation and validation study. Thorax 2003; 58(5) : 377-382.

8. Chidiac C, Che D, Pires-Cronenberger S, et al. Factors associated with hospital mortality in community-acquired legionellosis in France. Eur Respir J Oct 20, 2011 [cited Nov.14, 2011]. Available from:URL:http://erj.ersjournals. com/content/early/2011/10/18/09031936.00076911.long

9. Valencia M, Badia JR, Cavalcanti M, et al. Pneumonia severity index class $\mathrm{v}$ patients with community-acquired pneumonia: Characteristics, outcomes, and value of severity scores. Chest $207 ; 132(2): 515-522$.
10. Chalmers JD, Mandal P, Singanayagam A, et al. Severity assessment tools to guide ICU admission in communityacquired pneumonia: Systematic review and meta-analysis. Intensive Care Med 2011; 37(9) : 1409-1420.

11. Rello J, Rodriguez A, Lisboa T, et al. PIRO score for community-acquired pneumonia: A new prediction rule for assessment of severity in intensive care unit patients with community-acquired pneumonia. Crit Care Med 2009; $37(2): 456-462$

12. Jones BE, Jones J, Bewick T, et al. CURB-65 pneumonia severity assessment adapted for electronic decision support. Chest $2011 ; 140(1)$ : 156-163. 